\title{
Nitrat İndirgenmesinde Nano Ölçekli Sıfır Değerlikli Demir (nZVI) Kullanımı
}

\author{
Hande TÜRK ${ }^{1 *}$, Özge HANAY ${ }^{2}$ \\ ${ }^{1}$ Fırat Üniversitesi, Çevre Mühendisliği Bölümü, Elazı ̆ \\ ${ }^{2}$ Fırat Üniversitesi, Çevre Mühendisliği Bölümü, Elazı̆̆
}

\begin{abstract}
Özet
Nitrat yeraltı ve yüzeysel sulardaki kirletici unsurlardan biridir ve bu nedenle nitrat indirgenmesinde şimdiye kadar birçok farklı proses araştırılmıştır. Biyotik ve abiyotik olarak gerçekleştirilen nitrat indirgenmesinde çok çeşitli alternatifler mevcuttur. Bir diğer yönden nano ölçekli sıfir değerlikli demir (nZVI) atıksulardaki birçok kirleticinin giderimi için kullanılmaktadır. nZVI elektron verici özelliğinden dolayı daha çok kirleticilerin indirgenme çalışmalarında yer almıştır. Literatürde yer alan çalışmalar biyotik ve abiyotik indirgenmenin arka arkaya gerçekleştiği nZVI ile ototrofik denitrifikasyonun, bakteri-nZVI iş birliğinden dolayı diğer yöntemlere göre daha avantajlı olduğunu göstermektedir. Bu çalışmada da nitrat indirgenmesinde nZVI kullanımının rolü, avantajları ve indirgenme mekanizması, yapılan araştırmalardan derlenerek sunulmuştur.
\end{abstract}

Anahtar kelimeler: Nano Ölçekli Sıfır Değerlikli Demir, Nitrat İndirgenmesi, Biyotik Denitrifikasyon, Abiyotik Denitrifikasyon.

\section{Use of Nanoscale Zero Valent Iron (nZVI) in Nitrate Reduction}

\begin{abstract}
Nitrate is one of the pollutants in ground and surface waters and many different processes have been investigated up to now for nitrate reduction. There are various alternatives in biotic and abiotic nitrate reductions. On the other hand, nanoscale zero valent iron (nZVI) is used for the removal of many pollutants in wastewater. nZVI is nature electron donor, this leads its usage in many pollutants reduction. The researches in the literature show that autotrophic denitrification with nZVI, which is performed successively of biotic and abiotic reduction, is more advantageous than other methods due to the bacteria nZVI cooperation. In this study, the role of nZVI, the advantages and the mechanism of reduction in the reduction of nitrate, are presented by reviewing previous studies.
\end{abstract}

Keywords: Nanoscale Zero Valent Iron, Reduction of Nitrate, Biotic Denitrification, Abiotic Denitrification.

\section{Giriş}

Nitrat giderimi için alternatif yaklaşımlardan en yaygın olanı, nitratın amonyum yerine herhangi bir toksik etkisi olmayan azot gazına indirgendiği biyolojik denitrifikasyondur. İyon değiştirme ve ters osmoz süreçlerine kıyasla biyolojik denitrifikasyon potansiyel olarak daha düşük maliyetli bir alternatiftir [1]. Fakat özellikle heterotrofik bakteri kullanıldığında biyolojik denitrifikasyon, aşırı biyokütle problemine ve çözünebilir ürünlerin oluşumuna neden olduğu için ikincil arıtım ihtiyacı ortaya çıkabilir [2]. Elektron verici olarak hidrojenin kullanıldığ 1 ototrofik denitrifikasyon ile daha az biyokütle oluşur, sonuç olarak daha iyi nitrat giderimi sağlanabilir [2-3,4,5,6,7,8,9], hidrojenin kullanıldığı ototrofik denitrifikasyon reaksiyon (1)'de tanımlanmıştır [10].

*Sorumlu yazar: hande.turk89@gmail.com

Geliş Tarihi: 24/05/2017 Kabul Tarihi: 17/10/2017 
$0.33 \mathrm{NO}_{3}+\mathrm{H}_{2}+0.08 \mathrm{CO}_{2}+0.34 \mathrm{H}^{+} \rightarrow 0.015 \mathrm{C}_{5} \mathrm{H}_{7} \mathrm{O}_{2} \mathrm{~N}+0.16 \mathrm{~N}_{2}+1.11 \mathrm{H}_{2} \mathrm{O}$

Ototrofik denitrifikasyon mikroorganizmaları, besin kaynağı olarak inorganik karbona ve nitratı azot gazına indirgemek için hidrojen ya da indirgenmiş kükürt bileşenleri gibi elektron vericilere ihtiyaç duyarlar. Bu elektron verici kaynaklar, hidrojen [11], tiyosülfat [12-13] ve sülfür [14] gibi bileşenlerdir. Denitrifikasyon sürecinde hidrojeni enerji kaynağı olarak kullanan mikroorganizmalar doğada bolca bulunurlar [1-15]. Chang vd., (1999) hidrojen kullanan denitrifikasyon mikroorganizması olan Alcaligenes ototrofunun poliakrilamid ve aljinat kopolimerinde tutunarak denitrifikasyon verimini araştırılmışlardır. Bakterilerin yüksek nitrat yüklemelerine uyum sağladığını gözlemlemişlerdir [16].

Hidrojen gazının patlayıcı özelliğe sahip olması, depolama ve saklama sırasında meydana gelebilecek tehlikeleri ve nispeten pahalı olması, nitrat bazlı solunumdaki kullanımını sınırlar [17]. Hidrojen gazının üretimi ve tedariğinde belirtilen bu problemlerin varlığı denitrifikasyon sistemlerinin maliyetini yükseltir. $\mathrm{Bu}$ problemlerin üstesinden gelmek için reaksiyon ortamında hidrojeni oluşturabilen alternatif yaklaşımlar araştırılmıştır. Sıfır değerlikli demir (ZVI) önemli bir alternatif olarak Till vd., (1998) tarafından araştırılmış [1] ve denitrifikasyon sistemlerinde hidrojen ile ilgili problemlerin üstesinden anaerobik demir korozyonu (reaksiyon (2)) ile gelinebileceğini açıklamışlardır [18, 1, 16, 19].

$\mathrm{Fe}^{0}+2 \mathrm{H}_{2} \mathrm{O} \rightarrow \mathrm{H}_{2}+\mathrm{Fe}^{2+}+2 \mathrm{OH}^{-}$

Literatürdeki çalışmalar, nitrat gideriminde ZVI kullanımının amonyum üretimine neden olduğunu ve bu nedenle $\mathrm{pH}$ kontrolünün gerekliliğini anlatmaktadır. Son zamanlarda nitrat indirgenmesi için yapılan çalışmalar granüler ZVI'ya kıyasla daha geniş spesifik yüzey alanı ve daha yüksek yüzey reaktitivitesine sahip olduğu için nano ölçekli sıfır değerlikli demir (nZVI) ile gerçekleştirilmektedir [20]. Shin vd., (2008) nZVI'nın denitrifikasyon verimini artırmasının yanı sıra nZVI'nın yüksek seviyedeki indirgeyici kapasitesinden dolayı daha fazla miktarda amonyum üretimine neden olabileceğini açıklamışlardır [21]. Abiyotik nitrat indirgenmesi için Huang vd., (1998) tarafından tanımlanan reaksiyon (3) şu şekilde tanımlanmıştır [22]:

$\mathrm{NO}_{3}^{-}+4 \mathrm{Fe}^{0}+10 \mathrm{H}^{+} \rightarrow 4 \mathrm{Fe}^{2+}+\mathrm{NH}_{4}^{+}+3 \mathrm{H}_{2} \mathrm{O}$

Reaksiyon (3)'e göre nZVI'nın kimyasal indirgenmesiyle yüksek miktarda amonyum üretilebilir bu da ikincil arıtım ihtiyacının doğmasına neden olabilir [20]. Ayrıca bu reaksiyon sonucunda oluşan $\mathrm{Fe}^{2+}$ oksijensiz koşulların hakim olduğunu göstermektedir.

\section{2. Çevre Teknolojilerinde nZVI Kullanımı}

nZVI'nın toksik olmaması, ucuz ve çevreye uygun olması onu alternatif bir arıtım seçeneği yapmıştır. Nanopartiküller, kimyasal özellikleri ile birçok kirleticilerin arıtımı için uygun bir seçenektir [23-24] Yüzey alanlarının artması ile reaktivitelerinin artması en önemli avantajlarındandır [25-26].

Metalik nanopartiküllerin üretimi için 'bottom up' ve 'top down' olmak üzere 2 metot yaygın olarak kullanılmaktadır. Bottom up metodu, atom ya da molekül gibi temel yapı taşlarından nanomataryal oluşturan yaklaşımlarken top down metodu ise materyali nano boyuta parçalayan ve yeniden yapılandıran fiziksel ve kimyasal yaklaşımlardır [27]. Bottom up yöntemi, reaksiyon (4)'e göre Fe (II) ya da Fe (III) tuzları ve sodyum borhidrür indirgenmesi ile nZVI üretimini gerçekleştirir [28]. 
$4 \mathrm{Fe}^{3+}+3 \mathrm{BH}_{4}^{-}+9 \mathrm{H}_{2} \mathrm{O} \rightarrow 4 \mathrm{Fe}^{0} \downarrow+3 \mathrm{H}_{2} \mathrm{BO}_{3}^{-}+12 \mathrm{H}^{+}+6 \mathrm{H}_{2} \uparrow$

nZVI sulu ortamlarda zamanla magnetit, maghemit, lepidokrosit ve geotit gibi farklı demir oksit formlarına dönüşür [29-30]. Yapılan araştırmalar, nZVI'nın su ve çözünmüş oksijenin yanı sıra çeşitli çevresel kirleticiler ile de reaksiyona girebildiğini, kirleticilere karşı etkili ve uygun maliyetli arıtım seçeneği olduğunu göstermiştir. nZVI ile kirleticiler, indirgenerek ya da adsorbe edilerek giderilir. Örneğin, klorlu solventler gibi kirleticilerin giderimi indirgenme ile sağlanırken arsenik demir oksitlere adsorbe edilerek giderilir ve oksidasyon boyunca hidroksitler oluşur [29].

nZVI, klorlu hidrokarbonlar, poliklorlu bifenil, klorlu etenler, $\mathrm{Pb}^{2+}, \mathrm{Cr}^{6+}, \mathrm{Ni}^{2+}, \mathrm{As}^{3+}, \mathrm{As}^{5+}, \mathrm{Cd}^{2+}, \mathrm{Cu}^{2+}$, $\mathrm{Zn}^{2+}, \mathrm{Co}^{2+}$ gibi ağır metaller [31] ve inorganik anyonlar, nitrat, sülfat, fosfat çeşitli organik bileşenler ve inorganik katyon/anyonlar gibi çeşitli organik ve inorganik bileşenlerin giderimi için çeşitli çalışmalarda kullanılmıştır [32]. Literatürde yapılan bu çalışmalarda, Li vd., (2017), ağır metal içeren suların arıtımı için nZVI'nın ideal bir reaktif olduğunu [33], Dutta vd., (2016), ise yaptıkları çalışmada nZVI'nın tekstil atıksularından boya gideriminde uygun bir alternatif olabileceğini [34] Wang vd., (2016), $\mathrm{Pb}$ (II) ve $\mathrm{Zn}$ (II) giderimi için nZVI ve kireci karşılaştırmışlar ve çalışma sonucunda nZVI'nın $\mathrm{Pb}$ (II) ve $\mathrm{Zn}$ (II) gideriminde kirece kiyasla önemli avantajlara sahip olduğunu [35] ve Zhang vd., (2010), nZVI ile nitrat indirgenmesini gerçekleştirebileceklerini bildirmişlerdir [36].

\section{Biyolojik Denitrifikasyon}

Konvansiyonel nitrat giderim yöntemlerin pahalı olması, sonraki arıtım süreçleri ve yan ürünlerinin oluşumu nedeniyle ilgili bazı dezavantajları bulunmaktadır [37]. Nitrat giderimi için kullanılan teknolojilerin karşılaştırmalı gösterimi Tablo 1'de verilmiştir [38].

Tablo 1. Nitrat giderim yöntemlerinin karşılaştırılması [38]

\begin{tabular}{|c|c|c|c|c|}
\hline İyon Değiştirme & Ters Osmoz & Adsorpsiyon & Kimyasal Metotlar & Biyolojik Metotlar \\
\hline $\begin{array}{c}\text { Oluşan tuzlu } \\
\text { atıksuyun bertarafı } \\
\text { gerekir }\end{array}$ & $\begin{array}{l}\text { TDS (Toplam } \\
\text { Çözünmüş Katı) } \\
\text { bertarafı gerekir }\end{array}$ & $\begin{array}{l}\text { Adsorbent bertarafi } \\
\text { gerekir }\end{array}$ & $\begin{array}{l}\text { Atık bertarafi } \\
\text { gerekmez }\end{array}$ & $\begin{array}{l}\text { Biyokütle atığının } \\
\text { bertarafı gerekir }\end{array}$ \\
\hline $\begin{array}{l}\mathrm{pH} \text { ve sicaklık } \\
\text { önemli değildir }\end{array}$ & $\begin{array}{l}\mathrm{pH} \text { ve sıcaklık } \\
\text { önemli değildir }\end{array}$ & $\begin{array}{l}\text { pH ve sicaklık } \\
\text { önemlidir }\end{array}$ & $\begin{array}{l}\mathrm{pH} \text { ve sicaklık } \\
\text { önemlidir }\end{array}$ & Sıcaklık önemlidir \\
\hline $\begin{array}{l}\text { Oluşan suyun } \\
\text { korozif özelliğinin } \\
\text { giderilmesi için son } \\
\text { arıtım gerektirir }\end{array}$ & $\begin{array}{l}\text { Oluşan suyun } \\
\text { korozif özelliğinin } \\
\text { giderilmesi için son } \\
\text { arıtım gerektirir }\end{array}$ & $\begin{array}{l}\text { Genellikle son } \\
\text { aritım gerekmez }\end{array}$ & $\begin{array}{c}\text { Yan ürünlerin } \\
\text { oluşumu nedeniyle } \\
\text { son arıtım gerekir }\end{array}$ & $\begin{array}{l}\text { Mikroorganizmalar } \\
\text { nedeniyle son } \\
\text { arıtım gerekir }\end{array}$ \\
\hline $\begin{array}{c}\text { Yaklaşık 90\% } \\
\text { giderim verimi elde } \\
\text { edilir }\end{array}$ & $\begin{array}{c}>\% 95 \text { giderim } \\
\text { verimi elde edilir }\end{array}$ & $\begin{array}{l}\text { Giderim verimi } \\
\text { adsorbent çeşidine } \\
\text { göre farklılık } \\
\text { gösterir }\end{array}$ & $\begin{array}{l}>\% 60-70 \text { giderim } \\
\text { verimi elde edilir }\end{array}$ & $\begin{array}{c}>\% 99 \text { giderim } \\
\text { verimi elde edilir }\end{array}$ \\
\hline $\begin{array}{l}\text { İşletme maliyeti çok } \\
\text { yüksek değildir }\end{array}$ & $\begin{array}{l}\text { İşletme maliyeti } \\
\text { yüksektir }\end{array}$ & $\begin{array}{l}\text { İşetme maliyeti çok } \\
\text { yüksek değildir }\end{array}$ & $\begin{array}{l}\text { İşletme maliyeti } \\
\text { yüksektir }\end{array}$ & $\begin{array}{l}\text { İşletme maliyeti } \\
\text { çok yüksek değildir }\end{array}$ \\
\hline
\end{tabular}

Biyolojik denitrifikasyon, mikroorganizmalar ile nitratın sulu ortamlardan uzaklaştırılmasını sağlayan bir süreçtir. Nitrat solunumu olarak da adlandırılan bu süreçte nitrat, zararsız azot gazına dönüştürülür [39]. Biyolojik denitrifikasyon, moleküler oksijenin bulunmadığ 1 ve son elektron alıcı olarak nitratın kullanıldığı anoksik bir süreçtir. Bu süreçteki dönüşümler her biri ayrı enzim sistemi tarafindan katalizlenen dört adımda $\mathrm{NO}_{3} \rightarrow \mathrm{NO}_{2} \rightarrow \mathrm{NO} \rightarrow \mathrm{N}_{2} \mathrm{O} \rightarrow \mathrm{N}_{2}$ gerçekleşmektedir [11]. Denitrifikasyon mikroorganizmaları çoğu zorunlu anaerob olmayan fakültatif organizmalardır. En bilinen denitrifikasyon mikroorganizmaları: Achromobacter, Alcaligenes, Bacillus, Chrombacter, 
Corynebacterium, Halobacterium, Methanomonas, Moraxella, Paracoccus, Propionibacterium, Pseudomonas, Spirillum, Thiobacillus, ve Xanthomonas'dır [40-401]. Organik karbon kaynağına göre denitrifikasyon, ototrofik ve heterotrofik denitrifikasyon olarak iki grupta incelebilir [42,43]. İki grup arasındaki temel farklılık elektron alıcılarının farklı kaynaklar olmasıdır [44].

\subsection{Heterotrofik Denitrifikasyon}

Metabolizmaları için indirgenmiş organik substrata ihtiyaç duyan heterotrofik denitrifikasyon mikroorganizmaları, glikoz, metanol, etanol ve asetik asit gibi farklı organik karbon kaynaklarını elektron vericisi olarak kullanabilirler [45]. Reaksiyon 5, 6 ve 7'de metanol, etanol ve asetik asit için stokiometrik bağıntılar verilmiştir.

\section{Metanol}

$5 \mathrm{CH}_{3} \mathrm{OH}+6 \mathrm{NO}_{3}^{-} \rightarrow 3 \mathrm{~N}_{2}+5 \mathrm{CO}_{2}+7 \mathrm{H}_{2} \mathrm{O}+6 \mathrm{OH}^{-}$

\section{Etanol}

$5 \mathrm{C}_{2} \mathrm{H}_{5} \mathrm{OH}+12 \mathrm{NO}_{3}^{-} \rightarrow 6 \mathrm{~N}_{2}+10 \mathrm{CO}_{2}+9 \mathrm{H}_{2} \mathrm{O}+12 \mathrm{OH}^{-}$

\section{Asetik Asit}

$5 \mathrm{CH}_{3} \mathrm{COOH}+8 \mathrm{NO}_{3}^{-} \rightarrow 4 \mathrm{~N}_{2}+10 \mathrm{CO}_{2}+6 \mathrm{H}_{2} \mathrm{O}+8 \mathrm{OH}^{-}$

Bu substratlar su ya da arıtılacak atıksu içerisinde bulunmayabilir ve ortama ilave edilmesi gerekir. Örneğin, yüksek nitrat konsantrasyonuna sahip atık sularda azotun biyolojik giderimi, denitrifikasyon bakterilerinin ihtiyaç duyduğu karbon kaynaklarının düşük konsantrasyonda olmasından dolayı problemdir [46]. Bu nedenle birçok araştırmac1, organik karbon konsantrasyonun düşük olduğu su ve atıksulara metanol, etanol, asetik asit, glikoz ya da nişasta gibi karbon kaynaklarını ekleyerek denitrifikasyonun devam edebileceğini kanıtlamışlardır [47-48]. Maliyet, kapasite, reaktör konfigürasyonu ve denitrifikasyon suyunun son arıtımı gibi faktörler substrat seçiminde önemli parametrelerdir [49]. Heterotrofik denitrifikasyonda kullanılan bazı organik karbon kaynakları toksiktir, bunların kalıntılarının ve yan ürünlerinin giderimi için ileri arıtım süreçlerine ihtiyaç duyulabilir [37, 50]. Ayrıca karbon kaynağının türü, konsantrasyonu ve $\mathrm{C} / \mathrm{N}$ oranı da denitrifikasyon hızını etkileyen etmenlerdir [37, 51, 52, 53]. Düşük bir $\mathrm{C} / \mathrm{N}$ oranı denitrifikasyonun düzgün bir şekilde ilerlemesini engellerken, yüksek $\mathrm{C} / \mathrm{N}$ oranı da nitrit birikimine sebep olabilir ya da azot gazı dışında azotlu bileşiklerin oluşumuna yol açabilir [48-54]. Ototrofik denitrifikasyon mikroorganizmaları ise inorganik karbon kaynaklarını (karbondioksit ya da bikarbonat) besin kaynağı olarak kullanırlar ve enerji kaynağı olarak da hidrojen ya da indirgenmiş sülfür bileşiklerine elektron verici olarak ihtiyaç duyarlar [16]. Heterotrofik biyolojik denitrifikasyon da yüksek nitrat giderimine sahiptir ancak bu proseste ön arıtım karmaşık ve uzundur. Yeterli karbon kaynağının olması durumunda heterotrofik denitrifikasyon nitrat gideriminde verimlidir, ancak göl gibi karbon kaynağının yetersiz olduğu sularda organik substrat eklenmezse bu prosesin uygulanması verimli değildir [45].

\subsection{Ototrofik Denitrifikasyon}

Nitratın, Thiobacillus, Thiomicrospira, Paracoccus gibi ototrofik denitrfikasyon mikroorganizmaları tarafından azot gazına dönüştürüldüğü sürece ototrofik denitrifikasyon denir [55]. Bu süreçte ototrofik denitrifikasyon mikroorganizmaları elektron verici kaynak olarak hidrojen, indirgenmiş sülfür, manganez ve demir türleri gibi inorganik bileşikleri kullanabilirler [53]. Hidrojen ve tiyosülfat için stokiometrik ilişkiler reaksiyon (8) ve (9)'da verilmiştir [55]. 


\section{Hidrojen}

$2 \mathrm{NO}_{3}^{-}+5 \mathrm{H}_{2} \rightarrow \mathrm{N}_{2}+4 \mathrm{H}_{2} \mathrm{O}+2 \mathrm{OH}^{-}$

Tiyosülfat

$5 \mathrm{~S}_{2} \mathrm{O}_{3}^{2-}+8 \mathrm{NO}_{3}^{-}+\mathrm{H}_{2} \mathrm{O} \rightarrow 4 \mathrm{~N}_{2}+10 \mathrm{SO}_{4}^{2-}+2 \mathrm{H}^{+}$

Ototrofik büyüyen bakteriler için organik karbon kaynağ gerekmez, karbondioksit veya bikarbonat gibi inorganik karbon bileşiklerini hücre sentezi için karbon kaynağı olarak kullanırlar ancak Thiobacillus ve Paracoccus denitrifikasyon mikroorganizmaları ortamda organik karbon kaynağı varsa, heterotrofik olarak büyüyebilir [56].

Ototrofik denitrifikasyon, organik karbon kaynağına ihtiyaç duymaması, maliyetinin düşük olması ve daha az çamur üreterek son arıtım prosesi maliyetini düşürmesi gibi avantajlara sahiptir. $\mathrm{Bu}$ avantajlarına rağmen ototrofik mikroorganizmaların büyüme hızları, inorganik bileşenleri kullandıkları için yavaştır [37-54].

\subsection{1. nZVI ile Ototrofik Denitrifikasyon}

Biyolojik denitrifikasyonda nZVI kullanımı, hidrojen gazı ve organik substratların kullanımına bağlı olan problemleri ortadan kaldırabilir ve nZVI ile nitratın kısa sürede tamamen indirgenmesi gerçekleşebilir [21]. Ayrıca nZVI, ve ototrofik bakterilerin birlikte kullanıldığı nitrat indirgenmesi prosesinde amonyum oluşumu belirgin bir şekilde düşürülebilir. Böylece biyo-nZVI sinerjistik sistem ile daha düşük amonyum üretilerek nitrat indirgenmesi gerçekleştirilebilir [20]. An vd., (2009), nitrat arıtımında nZVI ve bir hidrogenotrofik bakteri olan Alcaligenes ototrofu kullanarak nitrat giderimini gerçekleştirmiştir. nZVI partikülleri ve bakteri içeren reaktörde nitrat 8 gün içerisinde tamamen giderilirken amonyum oluşumu \%33 olarak gözlenmiştir. İndirgenme hızının düşük olmasına rağmen amonyum oranı abiyotik reaktörlerdekine kıyasla daha düşüktür. Bakterinin kültürlenmesinden sonra birleştirilen nZVI-hücre sistemi amonyum çıkışı olmadan tüm nitratı giderebilmiştir. [20].

Abiyotik indirgenme periyodu ve biyolojik denitrifikasyon periyodu olarak nitrat giderimi, sinerjistik sistemde iki aşamaya bölünmüştür [57]. İlk olarak amonyum üretimi hızı ile de uyumlu olan artan bir periyot gerçekleşirken ve ikinci aşamada stabil bir periyot oluşur. nZVI, nitratı sadece ilk periyotta indirgeyebilir ve nitratla temas edince amonyum üretilir. Bu periyotta ototrofik mikroorganizmalar, nitratı kullanmak için çok az aktivite ile bu evreye adapte olmaya çalışırlar. Daha sonra nZVI, bakteriler için bir hidrojen vericisine dönüşür ve bu periyotta amonyum miktarı sabit kalır, kalıntı nitrat bakteriler tarafından kullanılır. Nitrat indirgenmesinde biyokütlenin belirli bir konsantrasyona ulaşmasıyla olay kimyasal indirgenmeden biyolojik denitrifikasyona dönüşür [57]. Bu durum Şekil 1 'de şematik olarak verilmiştir [58]. 


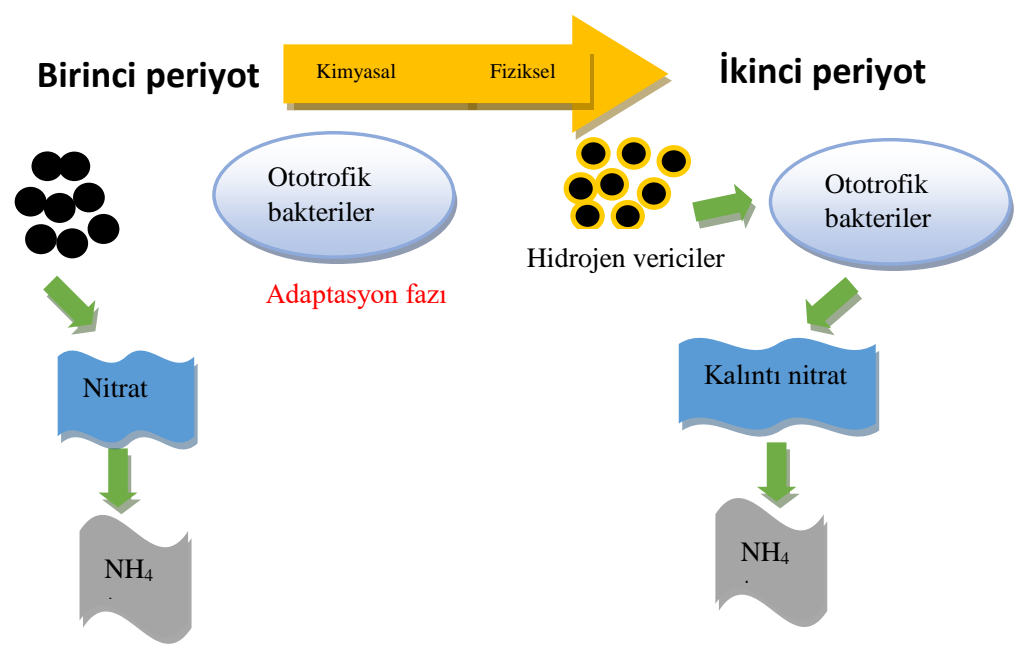

Şekil 1. Biyo-nZVI sinerjistik sistem ile nitrat giderim prosesi [58]

Literatürdeki çalışmalar incelendiğinde, Till vd., (1998) ve Kielemos vd, (2000), hem saf kültür (Paracoccus denitrifikatörü) hem de hidrogenotrofik denitrifikasyon mikroorganizmalarının karıșık bir kültürünü kullanarak anerobik demir korozyonu esnasında üretilen hidrojen gazı ile denitrifikasyonun devam edebileceğini göstermişlerdir [16]. Shin vd., 2008, biyolojik nitrat gideriminde nZVI kullanımının uygulanabilirliğini belirlemek için nZVI varlığında nitratın mikrobiyal indirgenmesini araştırmışlardır. Nitratın sadece \%50'si abiyotik olarak $25^{\circ} \mathrm{C}$ 'de 7 günde indirgenirken nZVI içeren reaktörde nitrat 3 gün içinde tamamen indirgenmiştir. Abiyotik indirgenmenin aksine nitratın mikrobiyal indirgenmesi düşük sıcaklık şartlarından etkilenmediği gözlenmiştir [21].

Suda hidrojenin düşük çözünürlüğe sahip olması çözünme ya da gaz fazdan sıvı faza hidrojenin zayıf kütle transferi ile ototrofik denitrifikasyonun hızını düşürebilir. Bu durumun üstesinden gelmek ve denitrifikasyonu tamamlayabilmek için temas süresi artırılabilir ve büyük hacimli biyoreaktörler gerekebilir [59].

Entegre denitrifikasyon süreçlerinde ototrofik bakterilerin (ör: Alcaligenes) sistem pH's1 ve nZVI yüzeyini değiştirmesi ve hatta nZVI oksidasyonunu hızlandırması nZVI ile aralarında bir rekabet oluşumuna neden olabilir. Yüksek bir pH değeri $(>8.0)$ elde edildiği için nZVI, okside bir demir tabakasının oluşumu ile pasifleşir ve bundan sonra nitrat indirgenmesinde bakteriler hakim olur [57]. Fazla miktarda bakteri, ciddi hücre birikimine neden olabileceği gibi nZVI yüzeyi ile daha az etkileşim gerçekleşmiş olur [20].

Yapılan bir çalışmada, yüksek miktarda nZVI kütlesi, hücrenin oksidatif hasarına yol açarak Fe(II) ve ROS'un (Reaktif Oksijen Türleri) aşırı alımı ile ototrofik bakterilere karşı belirgin bir toksisite göstermiştir [59]. Bu nedenle amonyum konsantrayonu yükselir ve nZVI'nın indirgeyici aktivitesi engellenir. Düşük konsantrasyonlarda bile nZVI toksik etkiler göstermesine karşın aerobik şartlar altında elektron kaynağı olarak 50-1000 mg/L nZVI eklenmesi, ototrofik mikroorganizmaların (ör: Paraccoccus) nitrat indirgenmesini artırabilir [60-61]. nZVI'nın bakterilere karş1 toksisitesi genellikle çevresel koşullardan etkilenmekle beraber bakteri türüne ve nZVI dozajına bağlıdır. nZVI oranı ve biyokütle konsantrasyonu optimize edilerek amonyum üretimi düşürülebilir, böylelikle denitrifikasyon verimi artır1lır [58].

Nitrat giderim sisteminde biyoinhibitör etkisini araştıran bir çalışmada indirgeyici olarak nZVI kullanılan sisteme hidrogenotrofik bakteri (HTB) eklenmiştir. İlave edilen HTB kültürünün (50-100 $\mathrm{mL}) \mathrm{nZVI}$ ile nitrat giderim hızının temsil edildiği ilk gözlemlenen hız sabitinde $\left(\mathrm{k}_{\mathrm{obs}}\right) \%$ 58,9-91,4 azalmaya neden olduğu ve oluşan zehirli ara ürünlerin \%94,9-38,5'e düştüğü gözlemlenmiştir [62].

nZVI ve mikroorganizmanın birlikte kullanıldığı sistemlerde oksijen, $\mathrm{pH}$, sıcaklık ve anaerobik korozyon ürünleri $\left(\mathrm{Fe}^{2+}, \mathrm{Fe}^{3+}\right.$ ve $\left.\mathrm{Fe}_{3} \mathrm{O}_{4}\right)$ gibi çeşitli faktörleri incelemek için Liu vd., (2014), nZVI ile 
önceden izole edilen Paracoccus sp. YF1 suşunu denitrifikasyonda kullanmışlardır. Sicaklık ve pH'nın ortamda nZVI bulunduğu ve nZVI olmadığ 1 durumlarda nitrat giderimini ve hücre büyümesini etkileyen esas faktörler olduğunu gözlemlemişlerdir. Anaerobik korozyon ürünleri $\mathrm{Fe}^{2+}$ ve $\mathrm{Fe}^{3+}$ 'e kıyasla $\mathrm{Fe}_{3} \mathrm{O}_{4}$ 'ün elektron vericisi olarak hizmet ederek denitrifikasyon işlemini hızlandırdığını belirtmişlerdir [61].

Sıfır değerlikli demirin reaktivitesini ve oksidasyona karşı direncini artırmak için nikel, bakır, paladyum ve bakır gibi metallerle kaplama çalışılmaları yapılmış ve ototrofik denitrifikasyonda da bu partiküllerden faydalanılmıştır. Örneğin, An vd., (2010), bimetalik ve polimer kaplı demir nanopartiküllerin biyolojik denitrifikasyona etkisini araştırmışlardır. $\mathrm{Bu}$ amaçla bimetalik demir nanopartikülleri (nano $\mathrm{Fe}-\mathrm{Ni}$, nano $\mathrm{Fe}-\mathrm{Cu}$ ) ve kaplı demir nanopartikülleri (kitosan-Fe ${ }^{0}$, sodyum oleat$\mathrm{Fe}$ ) ototrofik denitrifikasyonda kullanmışlardır. Nikel içeren nanopartiküllerin nZVI'ya kıyasla nitrat giderimini daha hızlı gerçekleştirdiğini ancak \%17 daha fazla amonyum üretildiğini gözlemlemişlerdir. $\mathrm{Fe}-\mathrm{Cu}$ prosesinin nitrat giderimini modifiye edilmemiş nZVI entegre sisteminden iki gün daha önce gerçekleştirdiğini ve amonyum miktarının \%13 azaldığını ancak nitritin büyük kısmının sistemde kaldığını gözlemlemişlerdir. nZVI partiküllerine kıyasla kitosan kaplı nanopartiküller nitratı aynı sürede gidermiş ancak kitosan kaplı nanaopartiküller ile \%23 daha az amonyum üretilmiştir. Sodyum oleat-Fe ${ }^{0}$ nanopartikülleri hem $\% 17$ amonyum üreterek amonyum miktarını azaltmış hem de nanopartiküllerin bakterilere karşı toksisitesini azaltmıştır [57]. Bimetaliklerle yapılan bir başka çalışmada, Dong vd., (2012), Alcaligenes ototrofu, nZVI ve bimetalik nanopartikül (nano $\mathrm{Fe} / \mathrm{Ni}$ ), kaplı demir nanopartikülün de (sodyum oleat- $\mathrm{Fe}^{0}$ nanopartiküller) mikroorganizmalar üzerindeki etkisini araştırmışlardır. Toksisite sıralaması; nano $\mathrm{Fe} / \mathrm{Ni}>\mathrm{nZVI}>$ sodyum oleat nanopartiküller olarak belirlenmiştir. nZVI'nın denitrifikasyon bakterileri için belirgin bir toksisiteye sahip olduğunu ancak nano materyalin yüzeyinin kaplanması ile toksisitenin azaltılabileceğini de belirtmişlerdir [63].

Metalik demir destekli hidrogenotrofik denitrifikasyon ile ilgili şu problemler de bulunmaktadır:

- Nitratın amonyağa abiyotik indirgenmesi biyolojik denitrifikasyona paralel olarak büyük miktarlarda amonyak üretimine neden olabilir.

- Hem biyolojik hem de abiyotik nitrat indirgenmesi sistemin pH'sını yükselterek $\mathrm{OH}^{-}$ üretimine neden olur. $\mathrm{pH}$ artışının olmaması ve nitrat indirgeme reaksiyonlarını etkilememesi için uygun tamponlama desteği sağlanmalıdır [16].

\section{4. nZVI ile Abiyotik Denitrifikasyon}

ZVI ile nitrat arasında gerçekleşen redoks reaksiyonu, ZVI'nın oksidatif çözünmesi sonucu metal iyonlarının oluşması ile gerçekleşir. Reaksiyon (10) şu şekildedir.

$F e^{0} \rightarrow F e^{2+}+2 e^{-}$

$\mathrm{Bu}$ durum nZVI'nın birçok redoks reaksiyonunda indirgeyici faktör olarak kullanılmasını sağlar. Nitrat indirgenmesi ile oluşabilecek muhtemel türler; nitrit, azot ve amonyak iken ZVI'nın $\mathrm{Fe}^{2+}$ iyonuna dönüştürülmesiyle gerçekleşen ZVI ile nitrat indirgenmesi prosesinde muhtemel ürünlerin amonyak, nitrit ve azot gazı oluştuğu reaksiyon (11) ve (12) ve (13)'te gösterilmiştir [64].

$4 \mathrm{Fe}^{0}+\mathrm{NO}_{3}^{-}+10 \mathrm{H}^{+} \rightarrow \mathrm{NH}_{4}^{+}+4 \mathrm{Fe}^{2+}+3 \mathrm{H}_{2} \mathrm{O}$

$\mathrm{Fe}^{0}+\mathrm{NO}_{\overline{3}}^{-}+2 \mathrm{H}^{+}+\rightarrow \mathrm{NO}_{2}^{-}+\mathrm{Fe}^{2+}+\mathrm{H}_{2} \mathrm{O}$ 
$5 \mathrm{Fe}^{0}+2 \mathrm{NO}_{3}^{-}+12 \mathrm{H}^{+} \rightarrow \mathrm{N}_{2(g)}+5 \mathrm{Fe}^{2+}+6 \mathrm{H}_{2} \mathrm{O}$

Choe vd., (2000), [65] belirli şartlar altında tamamen demir yardımı ile nitratın azot gazına abiyotik indirgendiğini ve indirgenmenin son ürünü olarak amonyak ve azot gazının oluştuğunu belirtmişlerdir [66-67]. Hu vd., (2001), nitrat indirgenmesi sırasında bir ara ürün olarak üretilen nitritin metalik demir ile amonyak ve azot gazına indirgendiğini yaptıkları bir çalışmayla kanıtlamışlardır [68]. Westerhoff ve James (2003), tarafından yapılan saha ölçekli bir çalışmada metalik demir içeren kolonlarda nitrat indirgenmesinin kolon çalışma zamanındaki artış ile dönüşüm yüzdesinin arttığını, uygulanan nitratın \%30-75'inin azot gazına gözle görünür şekilde dönüştüğünü bildirmişlerdir [69]. Sciliano (2015), özellikle $50 \mathrm{mg} / \mathrm{L}$ 'den daha yüksek nitrat konsantrasyonlarında arıtılan çözeltilerden nitratın hemen hemen tamamen indirgendiğini tespit etmiştir [70].

Reaksiyon şartlarını inceleyen Ziajahromi vd., (2013), başlangıç pH seviyesi, başlangıç nitrat konsantrasyonu ve başlangıç nano $\mathrm{Fe}^{0}$ dozajının nitrat indirgenmesi üzerine etkilerini araştırmışlardır. Başlangıç pH'sının artması ile nitrat indirgenme veriminin düştüğü ve nZVI'nın konsantrasyonunun artması ile giderim veriminde önemli bir artış olduğu sonucuna varmışlardır [71].

Kim vd., (2014), kanalizasyon sularından nitrat giderimi için nZVI'ya en uygun destek materyalini bulabilmek amacıyla nZVI, silika, sentetik zeolit ve bu üçlünün karışımını deneylerinde kullanmışlar sonuç olarak nZVI ile kimyasal denitrifikasyonun klasik kanalizasyon ve atıksu arıtma tesislerinde optimum şartlar altında nitrat giderimi için uygun olduğunu bunun yanı sıra silika ve zeolitin de uygun adsorbentler olduğunu belirtmişlerdir [72].

nZVI ile nitrat indirgenmesi prosesinde çözelti pH's1, kinetiği etkileyen en önemli faktördür $[73,67,74]$. Reaksiyon (14) ve (15)'e göre demir korozyonu ile nitrat indirgenmesinden alkalinite üretilir [75].

$$
\begin{aligned}
& 4 \mathrm{Fe}^{0}+\mathrm{NO}_{3}^{-}+7 \mathrm{H}_{2} \mathrm{O} \leftrightarrow 4 \mathrm{Fe}^{2+}+\mathrm{NH}_{4}^{+}+10 \mathrm{OH}^{-} \\
& \mathrm{Fe}^{0}+2 \mathrm{H}_{2} \mathrm{O} \leftrightarrow \mathrm{Fe}^{2+}+2 \mathrm{OH}^{-}
\end{aligned}
$$

Reaksiyon oranını korumak için kullanılan zayıf asitler, kullanılan diğer asitler veya tampon maddeler de reaksiyon oranlarını etkiler. $\mathrm{Fe}^{0}$ ile indirgenme prosesinde çeşitli tamponlama maddeleri [76-77] ve aynı fosfat tampon sistemi [78-73] ile $\mathrm{pH}$ değişimi test edilmiştir. Ancak farklı asitlerin ve pH'nın etkisi iyi tanımlanamamıştır [79]. Yang vd., (2005), kesikli deneylerle yaptıkları çalışmalarında çeşitli pH' larda nZVI ile nitratın kimyasal olarak indirgenmesini incelemişlerdir. Kuvvetli asidik şartların nitrat giderimi için daha uygun olacağını belirtmişlerdir [80]. Ziajahromi vd., (2012) sentezlenen nZVI partikülleri ile nitratın kimyasal indirgenmesini araştırmışlardır. Çalışmaları sonucunda nZVI'nın 0,25 g/L'den 1,0 g/L'ye artan dozaj1 ile pH'nın 4'ten 10'a artmasinın nitrat indirgenme verimini ciddi bir şekilde azalttığını görmüşlerdir [81]. Xu vd., (2012) tarafından yapılan bir başka çalışmada nitratın sıfır değerlikli demir $\left(\mathrm{Fe}^{0}\right)$ ile indirgenme veriminin nötr başlangıç şartları altında belli miktarda $\mathrm{Fe}^{2+}$ eklenmesi ile artacağını belirtmişlerdir. Proses boyunca $\mathrm{NO}_{3}{ }^{-}$ve $\mathrm{Fe}^{2+}$ konsantrasyonlarının azalma eğiliminde olduğu ancak sürecin üç aşamaya ayrıldığını bulmuşlardır. $\mathrm{Fe}^{2+}$ nin üretilen $\mathrm{Fe}_{3} \mathrm{O}_{4}$ ve sistemin $\mathrm{pH}$ tamponlamasında önemli rol alan iyonlaşan $\mathrm{H}^{+}$eşliğinde demir yüzeyinin korozyonunu artırdığını göstermişlerdir. Yaptıkları bu çalışmada $\mathrm{Fe}_{3} \mathrm{O}_{4}$, demir yüzeyine elektron transferini tercih eden iyi bir iletken olarak davrandığını ve $\mathrm{Fe}^{0}$ ve $\mathrm{Fe}^{2+}$ ile denitrifikasyon hızını arttırdığını belirtmişlerdir [82].

nZVI'nın aglomerasyonunu önlemek ve reaktivitesini arttırmak amacıyla çeşitli kaplama ve modifikasyon çalışmaları da yapılmıştır. Park vd., (2008), demir tuzlarının borhidrit ile indirgenmesini iyon değiştirici reçine varlığında etanol/su içeren bir dispersantta gerçekleştirmişlerdir. Nitrat indirgenmesi sonucunda klasik yöntemlerle hazırlanan nZVI'ya kıyasla etanol/su ile hazırlanan nZVI ile yalancı birinci dereceden hız sabitinin $61 \%$ arttığını belirtmişlerdir [83]. Park vd., (2009), bir diğer çalışmalarında nZVI aglomerasyonunu azaltmak için kullandıkları iyon değiştirme reçineleri ile 
hazırlanan nZVI ile nitrat indirgenmesinde en büyük problem olan amonyumun oluşmadığını gözlemlemişlerdir [84].

Khalil vd., (2016), nitrat giderimini $\mathrm{pH}$, oksijen varlı̆̆ı/yokluğu ve farklı nitrat konsantrasyonları (50, $100,200,300$ ve $500 \mathrm{mg} / \mathrm{L}$ ) ve farklı şartlar altında nZVI ve bakır tuzu ilave ederek ve ilave etmeden çalışmışlardır. Nitrat indirgenmesi süresince bakır iyonlarının varlığının iki elektrokimyasal reaksiyona neden olduğunu bunlardan birinin demir korozyonunu teşvik ettiğini diğer reaksiyonun hidrojen-elektrokatalik nitrat indirgenmesine neden olduğunu tespit etmişlerdir. Her iki tepkimenin giderim verimini ve kinetiklerini yalın nZVI'ya göre 3,5 kat arttırdığını, nitrat indirgenmesi süresini 1 saatten 20 dakikaya düşürdügünü de belirtmişledir [85].

\section{Sonuç ve Öneriler}

Atıksu arıtımında problem olan ve giderimi için çeşitli yöntemler bulunan nitrat için heterotrofik, ototrofik ve abiyotik denitrifikasyon prosesleri ile şu sonuçlara varılabilir:

- Ototrofik denitrifikasyon prosesinde elektron verici olarak pahalı olan ve depolanmasinda problemler olan hidrojen gazının kullanımı yerine nZVI'nın potansiyel kullanımı ve avantajları yapılan çalışmalarla da kanıtlanmıştır.

- Denitrifikasyon prosesi sırasında üretilen ve istenmeyen amonyum miktarının azaltılması için nZVI ile denitrifikasyon prosesine ototrofik mikroorganizmaların eklenmesi sistemin performansını artırarak amonyum miktarını düşürdüğü hatta bazı çalışmalarda hiç amonyum çıkışının olmadığı da kanıtlanmıştır.

- Nitrat indirgenmesinde heterotrofik denitrifikasyon yüksek nitrat giderim kapasitesine sahip iken ototrofik denitrifikasyon prosesinin daha az maliyetli olması, daha az çamur üretmesi, organik karbon kaynağ 1 gerektirmemesi gibi avantajlarından dolayı daha çok tercih edilir görülmektedir.

- Heterotrofik denitrifikasyon prosesinde kullanılan bazı organik karbon kaynaklarının kullanımına bağlı olarak suda kalıntılarının bulunması da heterotrofik prosesinin dezavantajlarından görülmektedir.

- Abiyotik denitrifikasyonun aksine nZVI ile ototrofik denitrifikasyonun düşük sıcaklıklardan etkilenmediği de çalışmalar sonucunda kanıtlanmıştır.

- Ototrofik denitrifikasyonun en önemli dezavantajı inorganik karbon kaynağını kullandıkları için bakterilerin büyüme hızlarının yavaş olması ve buna bağlı olarak denitrifikasyon prosesinin süresinin uzamasıdır, heterotrofik mikroorganizmalar organik karbon kaynağını kullandıkları için hızlı büyürler. 


\section{Kaynaklar}

1. Till B.A., Weathers L.J., Alvarez P.J.J. 1998. Fe(0)-Supported Autotrophic Denitrification, Environmental Science Technology, 32 (5): 634-639.

2. Mansell B.O., Schroeder E.D. 2002. Hydrogenotrophic Denitrification in Amicroporous Membrane Bioreactor, Water Research, 36 (19): 4683-4690.

3. Haring V., Conrad R. 1991. Kinetics of $\mathrm{H}_{2}$ Oxidation in Respiring and Denitrifying Paracoccusö Denitrificans, FEMS Microbiol Letters, 78 (2-3): 259-264.

4. Liessens J., Vanbrabant J., Vos P., Kersters K., Verstraete W. 1992. Mixed Culture Hydrogenotrophic Nitrate Reduction in Drinking Water, Microbial Ecology, 24 (3): 271-290.

5. Smith R.L., Ceazan M.L., Brooks M.H. 1994. Autotrophic, Hydrogen-Oxidizing, Denitrifying Bacteria in Groundwater, Potential Agents for Bioremediation of Nitrate Contamination, Applied and Environmental Microbiology, 60 (6): 1949-1955.

6. Ho C.M., Tseng S.K., Chang Y.J. 2001. Autotrophic Denitrification Via A Novel MembraneAttached Biofilm Reactor, Letters in Applied Microbiology, 33 (3): 201-205.

7. Smith R.L., Buckwalter S.P., Repert D.A., Miller D.N. 2005. Small-Scale, Hydrogen-Oxidizing Denitrifying Bioreactor for Treatment of Nitrate-Contaminated Drinking Water, Water Research, 39 (10): 2014-2023.

8. Vasiliadou I.A., Pavlou S., Vayenas D.V. 2006. A Kinetic Study of Hydrogenotrophic Denitrification, Process Biochemistry, 41 (6): 1401-1408.

9. Schnobrich M.R., Chaplin B.P., Semmens M.J., Novak P.J. 2007. Stimulating Hydrogenotrophic Denitrification in Simulated Groundwater Containing High Dissolved Oxygen and Nitrate Concentrations, Water Research, 41 (9): 1869-1876.

10. McCarty P.L. 1972. Stoichiometry of Biological Reactions, Proceedings of The International Conference Towards A Unified Concept of Biological Waste Treatment Design, Atlanta.

11. Kurt M., Dunn I.J., Bourne J.R. 1987. Biological Denitrification of Drinking Water Using Autotrophic Organisms with $\mathrm{H}_{2}$ in A Fluidized Bed Biofilm Reactor, Biotechnology and Bioengineering, 29 (4): 493-501.

12. Claus G., Kutzner H.J. 1985a. Autotrophic Denitrification by Thiobacillus Denitrificans in A Packed Bed Reactor, Applied Microbiology Biotechnology, 22 (4): 289- 296.

13. Claus G., Kutzner H.J. 1985b. Physiology and Kinetics of Autotrophic Denitrification by Thiobacillus Denitrificans, Applied Microbiology Biotechnology, 22 (4): 283-288.

14. Kleerebezem R., Mendezà, R. 2002. Autotrophic Dentrification for Combined Hydrogen Sulfide Removal From Biogas and Post Dentrification, Water Science Technology, 45 (10): 349-356.

15. Gamble T.N., Betlach M.R., Tiedje J.M. 1977. Numerically Dominant Denitrifying Bacteria From World Soils, Applied Environmental Microbiology, 33 (4): 926-939.

16. Chang C.C., Tseng S.K., Huang H.K. 1999. Hydrogenotrophic Denitrification with Immobilized Alcaligenes Eutrophus for Drinking Water Treatment, Bioresource Technology, 69 (1): 53-58. 
17. Biswas S., Bose P. 2005. Zero-Valent Iron-Assisted Autotrophic Denitrification, Journal Environmental Engineering, 131 (8): 1212-1220.

18. Kielemoes J., De Boever P., Verstraete W. 2000 Influence of Denitrification on The Corrosion of Iron and Stainless Steel Powder, Environmental Science Technology, 34 (4): 663-671.

19. Yu X.Y., Amrheinn C., Deshusses M.A., Matsumoto M.R. 2006. Perchlorate Reduction by Autotrophic Bacteria in The Presence of Zero-Valent Iron, Environmental Science Technology, 40 (4): 1328-1334.

20. An Y., Li T., Jin Z., Dong M., Li Q., Wang S. 2009. Decreasing Ammonium Generation Using Hydrogenotrophic Bacteria in The Process of Nitrate Reduction by Nanoscale Zero-Valent Iron, Science of The Total Environment, 407 (21): 5465-5470.

21. Shin K.H., Cha D.K. 2008. Microbial Reduction of Nitrate in The Presence of Nanoscale ZeroValent Iron, Chemosphere, 72 (2): 257-262.

22. Huang C.P., Wang H.W., Chiu C.P. 1998. Nitrate Reduction by Metallic Iron, Water Research, 32 (8): 2257-2264.

23. Zhang W.X. 2003. Nanoscale Iron Particles for Environmental Remediation: An Overview, Journal of Nanopartical Research, 5 (3): 323-332.

24. Zhang W.X. 2005. Nanoscale Environmental Science and Technology: Challenges and Opportunities, Environmental Science Technology, 39: 94A-95A.

25. Gotpagar J.K., Grulke E.A., Tsang T., Bhattacharyya D. 1997. Reductive Dehalogenation of Trichloroethylene Using Zero-Valent Iron, Environmental Progress and Sustainable Energy, 16 (2): 137-143.

26. Li F., Vipulanandan C., Mohanty K.K. 2003. Microemulsion and Solution Approaches to Nanoparticle Iron Production for Degradation of Trichloroethylene, Colloids and Surfaces A: Physicochemical and Engineering Aspects, 223 (1-3): 103-112.

27. Crane R.A., Scott T.B. 2012. Nanoscale Zero-Valent Iron: Future Prospects for An Emerging Water Treatment Technology, Journal of Hazardous Materials, 211-212: 112-125.

28. Wang C.B., Zhang W.X. 1997. Synthesizing Nanoscale Iron Particles for Rapid and Complete Dechlorination of TCE and PCBs, 31 (7): 2154-2156.

29. You Y., Han J., Chiu P.C., Jin Y. 2005. Removal and Inactivation of Waterborne Viruses Using Zero Valent Iron, Environmental Science and Technology, 39 (23): 9263-9269.

30. Phenrat T., Long T.C., Lowry G.V., Veronesi B. 2009. Partial Oxidation (“Aging”) and Surface Modification Decrease The Toxicity of Nanosized Zerovalent Iron, Environmental Science and Technology, 43 (1): 195-200.

31. Li X.Q., Zhang W. 2006. Iron Nanoparticles: The Core-Shell Structure and Unique Properties for Ni(II) Sequestration, Langmuir, 22 (10): 4638-4642.

32. Thiruvenkatachari R., Vigneswaran S., Naidu R. 2007. Permeable Reactive Barrier for Groundwater Remediation, Journal of Industrial and Engineering Chemistry, 14 (2): 145-156.

33. Li S., Wang W., Liang F., Zhang W. 2017. Heavy Metal Removal Using Nanoscale Zero-Valent Iron (nZVI): Theoryand Application, Journal of Hazardous Materials, 322 (A): 163-171. 
34. Dutta S., Saha R., Kalita H., Bezbaruah A.N. 2016. Rapid Reductive Degradation of Azo and Anthraquinone Dyes by Nanoscale Zero-Valent Iron, Environmental Technology \& Innovation, 5:176-187.

35. Wang W., Hua Y., Li S., Yan W., Zhang W. 2016. Removal of Pb(II) and Zn(II) Using Lime and Nanoscale Zero-Valent Iron (nZVI): A Comparative Study, Chemical Engineering and Journal, 304: 79-88.

36. Zhang J., Hao Z., Zhang Z., Yang Y., Xu X. 2010. Kinetics of Nitrate Reductive Denitrification by Nanoscale Zero-Valent Iron, Process Safety and Environmental Protection, 88 (6): 439-445.

37. Ghafari S., Hasan M., Aroua M.K. 2008. Bio-Electrochemical Removal of Nitrate From Water and Wastewater-A Review, Bioresource Technology, 99 (10): 3965-3974.

38. Bhatnagar A., Sillanpää M. 2011. A Review of Emerging Adsorbents for Nitrate Removal From Water, Chemical Engineering Journal, 168 (2): 493-504.

39. Shrimali M., Singh K.P. 2011. New Methods of Nitrate Removal From Water, Environmental Pollution, 112 (3): 351-359.

40. Zhao Y., Feng C., Wang Q., Yang Y., Zhang Z., Sugiura N. 2011. Nitrate Removal From Groundwater by Cooperating Heterotrophic With Autotrophic Denitrification in A BiofilmElectrode Reactor, Journals of Hazardous Materials, 192 (3): 1033-1039.

41. Koenig A., Zhang T., Liu L.H., Fang H.H. 2005. Microbial Community and Biochemistry Process in Autosulfurotrophic Denitrifying Biofilm, Chemosphere, 58 (8): 1041-1047.

42. Van H.M., Loosdrecht M.C.M., Heijnen J.J. 1999. Modelling Biological Phosphorus and Nitrogen Removal in A Full Scale Activated Sludge Process, Water Research, 33 (16): 34593468 .

43. Show K.Y., Lee D.J., Pan X. 2013. Simultaneous Biological Removal of Nitrogen-Sulfur-Carbon: Recent Advances and Challenges, Biotechnology Advances, 31 (4): 409-420.

44. Hamlin H. J., Michaels J. T., Beaulaton C. M., Graham W.F., Dutt W., Steinbach P., Losordo T.M., Schrader K.K., Main K.L. 2008. Comparing Denitrification Rates and Carbon Sources in Commercial Scale up Flow Denitrification Biologicalfilters in Aquaculture, Aquacultural Engineering, 38 (2): 79-92.

45. Van der Hoek J.P., Klapwijk A. 1988. The Use of A Nitrate Selective Resin in The Combined Ion Exchange/Biological Denitrification Process For Nitrate Removal From Groundwater, Water Supply, 6: 57-62.

46. Kim S., Jung H., Kim K.S., Kim I.S. 2004. Treatment of High Nitrate Containing Wastewaters by Sequential Heterotrophic and Autotrophic Denitrification, Journal of Environmental Engineering, 130 (12): $1475-1480$.

47. Killingstad M.W., Widdowson M.A., Smith R.L. 2002. Modeling Enhanced in Situ Denitrification in Groundwater, Journal of Environmental Engineering, 128 (6): 491-504.

48. Kim Y.S., Nakano K., Lee T.J., Kanchanatawee S., Matsumura M. 2002. On-Site Nitrate Removal of Groundwater by An Immobilized Psychrophilic Denitrifier Using Soluble Starch As A Carbon Source, Journal of Bioscience and Bioengineering, 93 (3): 303-308.

49. Szekeres S., Kiss I., Kalman M., Soares M.I.M. 2002. Microbial Population in A HydrogenDependent Denitrification Reactor, Water Research, 36 (16): 4088-4094. 
50. Feleke Z., Sakakibara Y. 2002. A Bio-Electrochemical Reactor Coupled with Adsorber for The Removal of Nitrate and Inhibitory Pesticide, Water Research, 36 (12): 3092-3102.

51. Galvez J.M., Gomez M.A., Hontoria E., Gonzalez-Lopez J. 2003. Influence of Hydraulic Loading and Air Flowrate on Urban Wastewater Nitrogen Removal with a Submerged Fixed-Film Reactor, Journal Hazardous Materials, 101 (2): 219-229.

52. Gomez M.A., Galvez J.M., Hontoria E., Gonzalez-Lopez J. 2003. Influence of Concentration on Biofilm Bacterial Composition From A Denitrifying Submerged Filter Used for Contaminated Groundwater, Journal Bioscience and Bioengeneering, 95 (3): 245-251.

53. Rijn J.V., Tal Y., Schreier H.J. 2006. Denitrification in Recirculating Systems: Theory and Applications, Aquacultural Engineering, 34 (3): 364-376.

54. Chiu Y.C., Chung M.S. 2003. Determination of Optimal COD/Nitrate Ratio for Biological Denitrification, International Biodeterioration \& Biodegradation, 51 (1): 43-49.

55. Beiki M.R., Yazdian F., Rasekh B., Rashedi H., Rostami A.D. 2016. Effect of Metal Nanoparticles on Biological Denitrification Process: A Review, Journal of Applied Biotechnology Reports, 3 (1): 353-358.

56. Gayle B.P., Boardman G. D., Sherrard J.H., Benoit R.E. 1989. Biological Denitrification of Water, Journal of Environmental Engineering, 115 (5): 930-943.

57. An Y., Li T., Jin Z., Dong M., Li Q. 2010. Nitrate Degradation and Kinetic A nalysis of The Denitrification System Composed of Iron Nanoparticles and Hydrogenotrophic Bacteria, Desalination, 252 (1-3): 71-74.

58. Xie Y., Dong H., Zeng G., Tang L., Jiang Z., Zhang C., Deng J., Zhang L., Zhang Y. 2017. The Interactions Between Nanoscale Zero-Valent Iron and Microbes in The Subsurface Environment: A Review, Journal of Hazardous Materials, 321 (5): 390-407.

59. Prosnansky M., Sakakibarab Y., Kuroda M. 2002. High-Rate Denitrification and SS Rejection by Biofilm-Electrode Reactor (BER) Combined with Microfiltration, Water Resource, 36 (19): 4801-4810.

60. Barnes R.J., Van der Gast C.J., Riba O., Lehtivirta L.E., Prosser J.I., Dobson P.J., Thomphson I.P. 2010. The Impact of Zero-Valent Iron Nanoparticles on A River Water Bacterial Community, Journal Hazardous Materials, 184 (1-3): 73-80.

61. Liu Y., Li S., Chen Z., Megharaj M., Naidu R. 2014. Influence of Zero-Valent Iron Nanoparticles on Nitrate Removal by Paracoccus sp, Chemosphere, 108: 426-432.

62. An Y., Dong Q., Zhang K. 2014. Bioinhibitory Effect of Hydrogenotrophic Bacteria on Nitrate Reduction by Nanoscale Zero-Valent Iron, Chemosphere, 103: 86-91.

63. Dong M.Y., Wang X., Huang F., Jin F.H., Li T.L. 2012. Toxicity of $\mathrm{Fe}^{0}$ Nanoparticles on the Denitrifying Bacteria-Alcaligenes Eutrophus, Advanced Materials Research, 343-344 (3): 889894.

64. Chen S.S., Hsu H.D., Li C.W. 2004. A New Method to Produce Nanoscale Iron for Nitrate Removal, Journal of Nanoparticle Research, 6 (6): 639-647.

65. Choe S., Chang Y.Y., Hwang K.Y., Khim J. 2000. Kinetics of Reductive Denitrification by Nanoscale Zero-Valent Iron, Chemosphere, 41 (8): 1307-1311. 
66. Chi I., Zhang S.T., Lu X., Dong L.H., Yao S.L. 2004. Chemical Reduction of Nitrate by Metallic Iron, Journal of Water Supply: Research and Technology-AQUA, 53 (1): 37-41.

67. Huang Y.H., Zhang T.C. 2002. Kinetics of Nitrate Reduction by Iron at Near Neutral pH, Journal of Environmental Engineering, 128 (7): 604-611.

68. Hu H.Y., Goto N., Fujie K. 2001. Effect of pH on The Reduction of Nitrite in Water by Metallic Iron, Water Research, 35 (11): 2789-2793.

69. Westerhoff P., James J. 2003. Nitrate Removal in Zero-Valent Iron Packed Columns, Water Research, 37 (8): 1818-1830.

70. Sciliano A. 2015. Use of Nanoscale Zero-Valent Iron (NZVI) Particles for Chemical Denitrification Under Different Operating Conditions, Metals, 5 (3): 1507-1519.

71. Ziajahromi S., Khanizadeh M., Khiadani M. 2013. Experimental Evaluation of Nitrate Reduction From Water Using Synthesis Nanoscale Zero-Valent Iron (NZVI) Under Aerobic Conditions, Middle-East Journal of Science Research, 16 (2): 205-209.

72. Kim M.S., Kwak D. H. 2014. Treatment Characteristics and Effects of Nanoparticle Zero-Valent Iron (nZVI) Powder on Nitrogen Removal Efficiency for Sewage Treatment, Water Quality Research Journal , 49 (3): 273-284.

73. Lavine B.K., Auslander G., Ritter J. 2001. Polarographic Studies of Zero Valent Iron as A Reductant for Remediation of Nitroaromatics in The Environment, Microchemical Journal, 70 (2): 69-83.

74. Alowitz M.J., Scherer M.M. 2002. Kinetics of Nitrate, Nitrite, and Cr(VI) Reduction by Iron Metal, Environmental Science Technology, 36 (3): 299-306.

75. Choe S., Liljestrand H.M., Khim J. 2004. Nitrate Reduction by Zero-Valent Iron Under Different pH Regimes, Applied Geochemistry, 19 (3): 335-342.

76. Matheson L.J., Tratnyek P.G. 1994. Abiotic and Biotic Aspects of Reductive Dechlorination of Chlorinated Solvents by Zerovalent Iron, Preprint of Extended Abstract, Presented at Division of Environmental Chemistry, Am. Chem. Soc., 13 March, San Diego, 720-723.

77. LipczyskaKochany E., Harms S., Milbum R., Sprah G., Nadarajah N. 1994. Degradation of Carbon Tetrachloride in The Presence of Iron and Sulphur Containing Compounds, Chemosphere, 29 (7): 1477-1489.

78. Chen J.L., Al-Abed S.R., Ryan J.A., Li Z. B. 2001. Effects of pH on Dechlorination of Trichloroethylene by Zero-Valent Iron, Journal Hazardous Materials, 83 (3): 243-254.

79. Agrawal A., Tratnyek P. G. 1995. Reduction of Nitro Aromatic Compounds by Zero-Valent Iron Metal, Environmental Science and Technology, 30 (1): 153-160.

80. Yang G.C.C., Lee H.L. 2005. Chemical Reduction of Nitrate by Nanosized Iron: Kinetics and Pathways, Water Research, 39 (5): 884-894.

81. Ziajahromi S., Mehrdad M. 2012. Nitrate Removal from Water Using Synthesis Nanoscale ZeroValent Iron (NZVI), Journal of International, 7 (5): 939-943.

82. Xu J., Hao Z., Xie C., Lv X., Yang Y., Xu X. 2012. Promotion Effect of $\mathrm{Fe}^{2+}$ and $\mathrm{Fe}_{3} \mathrm{O}_{4}$ on Nitrate Reduction Using Zero-Valent Iron, Desalination, 284: 9-13. 
83. Park H.S., Park Y.M., Oh S.K, Lee S.J., Choi Y.S., Lee S. H. 2008. Evaluation of Denitrification Reactivity by the Supported Nanoscale Zero-Valent Iron Prepared in Ethanol-Water Solution, The Korean Institute of Chemical Engineers, 46 (5): 1008-1012.

84. Park H.S., Park Y.M., Yoo K.M., Lee S.H. 2009. Reduction of Nitrate by Resin-Supported Nanoscale Zero-Valent Iron, Water Science and Technology, 59 (11): 2153-2157.

85. Khalil A.M.E., Eljamal O., Jribi S., Matsunaga M. 2016. Promoting Nitrate Reduction Kinetics by Nanoscale Zero Valent Iron in Water via Copper Salt Addition, Chemical Engineering Journal, 287 (1): 367-380. 